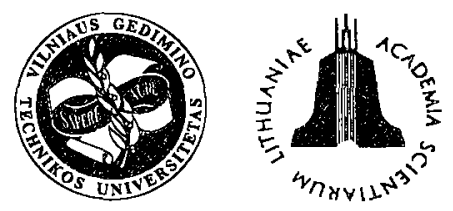

\title{
STRATEGIC PLANNING OF THE ROLLING STOCK IN TRANSPORTATION BY RAIL
}

\author{
Saulius Kaminskas
}

\author{
Department of Transport Management, Vilnius Gediminas Technical University, \\ Plytinés g.27,LT-2040 Vilnius,Lithuania.E-mail:kamis@takas.lt \\ Received 200206 26; accepted 20021020
}

\begin{abstract}
Planning the structure and volume of the rolling stock is a key factor of achieving maximum efficiency of transportation by rail as well as forecasting the demand for these transport facilities. The demand for trains is a time dependant variable which in each case should be determined by two main approaches. The first method allows us to determine quantitative parameters of rolling stock (i.e. kilometers logged, efficiency, turnover, etc.). The second is based on specially developed mathematical models relying on qualitative characteristics such as relative expenses, efficiency of the particular train, relative expenditure of resources, cost of the trains, etc.

Planning the volume of the rolling stock the determination of optimal service life of the trains plays an important role. The calculations involve repair costs, number of overhauls, current expenses and other operational characteristics.
\end{abstract}

Keywords. rail transport, trains, rolling stock.

\section{Introduction}

Developing strategies for effective national transportation by rail the existing structure of rolling stock should be analyzed and possible changes predicted. The rolling stock and the demand for it make a variable which may be calculated by the particular techniques. Some of them rely on the present situation when it is necessary to calculate the stock based on available quantitative data of the kilometers logged, efficiency, turmover, etc. The particular mathematical models are being developed for its quantitative evaluation taking into account relative expenses, the efficiency and cost of the particular rolling stock, and the like. Based on the above models it is possible to determine the optimal structure of the rolling stock as well as to predict its development and trade tendencies [1-3].

Making plans with account of possible changes in the rolling stock the optimal service life should also be determined, taking into consideration repair expenses, overhauls, current expenses and other maintenance factors $[4,5]$.

\section{Rail Transport of Lithuania}

In transportation by rail the serviceability of locomotives and other traction facilities determining the intensity, safety and efficiency of freight and passenger transportation play an important role. At present the locomotives, diesel and electric trains are used in Lithuania for this purpose. The locomotives (256) relying on inter- nal combustion diesel engines and electric drives make a major part of them.

The volume of planned freight and passenger transportation is a decisive factor of rational use of the rolling stock. In determining the demand for the locomotives, the efficiency of their operation should also be known.

In 1997 Lithuanian railway purchased 51 head wagons of European standard which have already been used. This enabled "Lithuanian Railway" to join the European stock of freight wagons (RIV) accepting their standards of wagon usage and stock - taking. The stock of head wagons and their demand in $2005-2010$ [6].

\begin{tabular}{|c|c|c|c|c|}
\hline Type of wagons & 2000 & 2005 & 2010 & 2015 \\
\hline Covered wagons & 1438 & 1327 & 1361 & 1334 \\
\hline Platform wagons & 1917 & 1769 & 1814 & 1779 \\
\hline Semi- wagons & 2108 & 1946 & 1996 & 1956 \\
\hline Cisterns & 2204 & 2035 & 2086 & 2045 \\
\hline Other & 1917 & 1769 & 1814 & 1779 \\
\hline Total & 9584 & 8846 & 9071 & 8893 \\
\hline
\end{tabular}

The amount of wagons available at present would satisfy the needs for transportation. However, most of them require repair, while some should be written off.

The demand of wagons was calculated determining the average number of loaded wagons accepted and trans- 
ferred per day (twenty four hours) and multiplying the sum obtained by the average wagon turnover in the particular period of time assuming that the latter is going to decrease (i.e. in 2005 it would make -4.5 days (24. hours each), in 2000 - 3.9 days and in 2015 - 3.3 days). The demand for specialized wagons was determined based on the expected demand for transportation of the particular type of cargo which is the main factor on which the demand depends.

\section{Models of Calculating the Amount of Trains Needed for Transportation by Rail}

In recent years the methods described in literature $[1,2]$ which had been created for calculating the traction rolling stock some years ago have been widely used. The above calculations are based on the coefficient of the demand for locomotives as well as on the demand on the particular route or for the rolling stock as a whole. Further we will consider the ways of calculating the railway wagons by the most accurate approach based on the time (hours) of the wagon as a constituent part of the train, the time of cargo transfer and maintenance or repair time.

$$
n_{d}=\frac{1}{24}\left(\frac{\sum n s}{v_{r}}+\sum n_{k} t_{k}+\sum n_{t} t_{t}\right),
$$

here $\frac{\sum n s}{v_{r}}-$ wagon - hours;

$\sum n s$ - distance run by the wagons [wagons - $\mathrm{km}$ ];

$v_{r}$ train speed at the route $[\mathrm{km} / \mathrm{h}]$;

$\sum n_{k} t_{k}$ - wagon - hours (cargo transfer);

$\sum n_{t} t_{t}$ - wagon - hours (maintenance).

Wagon stock with respect to an average distance run per day:

$$
n_{d}=\frac{\sum n_{k} s_{k}+\sum n_{t} s_{t}}{s_{B}}
$$

Wagon stock with respect to the efficiency per day:

$$
n_{d}=\frac{\sum p l}{F_{B}}
$$

The volume of the wagon stock operating at present can be determined based on wagon turnover per day $\vartheta$ (in days) and the work $u$ (for the particular route) or relying on an average cargo transfer per day in the wagons $\sum u_{p}$ (for the whole railway system), that is:

$$
n_{d}=\vartheta u
$$

or:

$$
n_{d}^{\prime}=\vartheta \sum u_{p}
$$

The inventory stock of freight wagons may be determined in this way:

$$
n_{i n v}=n_{d}(1+\beta)
$$

here $\beta$ is a coefficient to determine the number of wagons out of operation $(\beta=0.1-0.2)$.

The stock of passenger wagons in operation is as follows:

$$
n_{s k}^{p}=m z \vartheta_{s c i s t},
$$

here $m$-average number of wagons in the train; $\mathrm{z}$ - number of wagons on the route per day;

$\vartheta_{\text {sast }}$ - turnover of passenger trains.

The inventory stock of passenger wagons may be found in this way:

$$
n_{i n v}^{p}=n_{s k}^{p}\left(1+\beta_{s k}+\beta_{s p e c}\right)
$$

here $\beta_{s k}$-coefficient to determine the number of reserved or broken wagons $(\beta=0,06-0,09)$;

$\beta_{\text {spec }}$ - coefficient to determine specialized wagons $(\beta=0,01-0,02)$.

The calculations made by the above formula are based on the use of various coefficients, therefore their accuracy may range to some extent.

Theoretical analysis of rolling stocks may rely on the following statement: a variant requiring minimal total forced expenses should be chosen from a set of the alternative rolling stock structural patterns and purchasing variants ensuring the achievement of the final goal (i.e. good transportation in due time and at the costs specified).

Assuming the condition of linearity the model may be expressed in this way:

$$
\begin{aligned}
& \min \sum_{i, j} c_{i j} x_{i j} ; \\
& \sum_{j} a_{i j} x_{i j} \geq b_{i} ; \\
& \sum_{i, j} d_{i j}^{m} x_{i j} \leq R^{m} ; \\
& x_{i j} \geq 0,
\end{aligned}
$$

here $x_{i j}$ is the number of $\mathrm{j}-$ type trains used to carry prod ucts i (type of cargo, type of transportation):

$c_{i j}, a_{i j}, d_{i j}^{m}$ - relative forced expenses, efficiency of the particular train and relative expenditure of resource nin carrying $i$ - type cargo by $j$-type train, respectively.

The model (9) - (12) can not adequately describe the actual process.

First, the relative expenses $c_{i j}$ depend on the structure of the rolling stock $x_{i j}$, being, in fact, non - linear. Therefore, they should be described as follows:

$$
\begin{aligned}
& \sum_{i} c_{i j} x_{i j}=\sum_{i} \tilde{c}_{i j} x_{i j}+E K_{j} y_{j} s n y_{j} \\
& y_{j} \equiv x_{j}-x_{j}^{0}+x_{j}^{B}
\end{aligned}
$$


here $\tilde{c}_{i j}$ - average operational expenses in $i$-type

transportation by $j$ - type rolling stock (train);

$K_{j}$ - cost of a rolling stock;

$y_{j}$-purchasing of $j$ - type rolling stocks ( $x_{j}^{0}$ - at

the beginning of the year; $x_{j}^{B}$-purchasing completed)

The value (13) introduced is:

$$
\operatorname{sn} y=\left\{\begin{array}{l}
1, \text { if } y \geq 0 \\
0, \text { if } y<0
\end{array}\right.
$$

Therefore, the model (9) should be replaced by (13)-

Second, the above model is static, not taking into account the dynamics of transportation, wearing of the locomotives, strategies of their replacement and changes with time. In addition, the optimal technical parameters and maintenance characteristics should be chosen, which is of special importance when service life is considered. The latter is a decisive factor determining the number of trains to be purchased.

Let us consider an optimal model of rolling stock replenishment. Let us suppose that changing of technical and economical parameters is a discrete process with each train operating in the same mode for some time, then being transferred to another mode of operation because of aging. New trains are put into operation and old ones written off only at the end of the year. To simplify the model let us assume that both the trains used and cargo transported are of the same type. (However, the above simplification does not bring about any radical changes, making the formulation even more complicated, therefore, it may be omitted).

Let $\tau$ represent service life of the train; $r$ - operation mode; $N_{\tau r t}$ - number of trains with $\tau$ years of service operating in the year $\mathrm{t}$ of the planned period; $N_{\tau r^{-}}$- number of trains operating in mode r. Trains of each type are characterized by the efficiency current expenses $I_{\tau m}$ (which can be referred to those of renovation or repair, if necessary), replenishment cost $K_{\tau / \mathrm{t}}$ and dismantling (reduction) balance (cost of scrap metal minus reduction expenses $L_{\tau t}$ ).

Based on the assumptions made the replenishment of the rolling stock may be described by the following model:

$$
\begin{aligned}
& \sum_{t \geq 1} \frac{K_{0 t}}{(1+E)^{t-1}}+\sum_{t \geq 1} \sum_{\tau \geq 1} \sum_{r} \frac{I_{\tau r t} N_{\tau r t}}{(1+E)^{t}}-\sum_{\tau \geq 1} L_{\tau 1}\left(N_{\tau-1}^{0}-\right. \\
& \left.-N_{\tau 1}\right)-\sum_{t \geq 2 \tau>1} \sum_{\tau, t}^{L_{\tau t}\left(N_{\tau-1, t-1}-N_{\tau t}\right)} \\
& (1+E)^{t-1}
\end{aligned}
$$

for the constraints:

$$
\sum_{\tau \geq 0 r} \sum_{\tau r t} P_{\tau r t} \geq V_{t,}, \quad t \geq 1
$$

$$
\begin{aligned}
& \sum_{r} N_{\tau r t}=N_{\tau t}, \quad t \geq 1, \quad \tau \geq 0 ; \\
& N_{\tau 1} \leq N_{\tau-1}^{0}, \quad \tau \geq 1 ; \\
& N_{\tau t} \leq N_{\tau-1, t-1}, \quad t \geq 2, \quad \tau \geq 1,
\end{aligned}
$$

here $V_{l}$ - planned demand for transportation to be satisfied by trains during the year $t$;

$N_{\tau}^{0}$ - number of trains of t service life, when $t=0$;

$K_{0 t}, N_{0 t}$-number and cost of new trains in the year

$t$.

In economic terms (16) - (20) may be described in the following way. The efficiency function (16) tends to minimize the total major and current expenses to $t=0$ ( 1 - st and $2-d$ terms, respectively) by subtracting the sum obtained in dismantliilg trains during the whole period of renewal. The inequality (17) means the requirement to fully satisfy the demand for transportation. The inequality (18) shows that the number of trains operating in different modes should be equal to the total number of trains for the given time of operation. The balance inequalities (19) - (20) demonstrate that the number of trains of $\tau$ service life in the year t should not exceed that of the trains of $(\tau-1)$ service life in the last year of the planned period of time.

The model (16) - (20) enables us to determine not only the optimal structure of the rolling stock and purchase order, but the rate of the development of a given transport facility and trading tendency as well.

\section{Optimal Service Life of Rolling Stocks}

During their service life rolling stocks should bring profit to a state - owned or private company which may optimize their work based on the local efficiency criterion. This criterion may be taken as minimum relative expenses equated based on time factor and the moment of train purchasing, i.e. being, in fact, the relationship between the expenses on train purchasing, overhauls and operational expenses (minus dismantling balance) and the total volume of transportation carried out by all trains during their operation time.

Let us consider a model for determining the optimal service life of the train in accordance with the minimum relative forced expenses. As it had been done before, let us take a model where the process of wearing is discrete implying that during each year the technical and economic parameters of the trains are considered to be constant, while at the turn of the year they abruptly change.

The costs of purchasing the trains as well as the expenses on their overhauls and maintenance during the year $\tau$, minus the sum obtained after their dismantling (elimination) at the end of the last year of their service life equated to those existing at the moment before their purchasing based on the time factor are equal to: 


$$
K+\sum_{m=1}^{M} \frac{R_{m}}{(1+E)^{\tau_{m}}}+\sum_{t=1}^{T} \frac{I(t)}{(1+E)^{t}}-\frac{L}{(1+E)^{T}},
$$

here $K$ - initial cost of the trains;

$R_{m}$ - cost of repair;

$\tau_{m}$ - the year when repairs are to be made;

$M$ - number of overhauls;

$I(t)$ - current expenses (without those of renovation)

for the trains operating in the year $t$;

$L$ - cost of train dismantling (elimination).

The volume of transportation equated to that existing before train purchasing, based on the time factor, is equal to:

$$
\sum_{t=1}^{T} \frac{P(t)}{(1+E)^{t}}
$$

here $P(t)$ - the efficiency of trains in the year $\mathrm{t}$ of their operation.

The optimal service life $T$ should correspond to the minimum expenses on carrying the unit of cargo, i.e.:

$$
\min _{T} \frac{K+\sum_{m=1}^{M} \frac{R_{m}}{(1+E)^{\tau_{m}}}+\sum_{t=1}^{T} \frac{I(t)}{(1+E)^{t}}-\frac{L}{(1+E)^{T}}}{\sum_{t=1}^{T} \frac{P(t)}{(1+E)^{t}}}
$$

The functions describing the changes in current expenses and the efficiency of trains for any cycle of operation, i.e. including the time from new train purchasing to the first overhaul as well as from the first until the second overhaul, etc. may be of various nature. The value of the above functions depends on the time of operation calculated not from the moment of train purchasing, but from starting the cycle of operation. Therefore, the summation should be made for each particular cycle. In addition, decreasing relative expenses with respect to service life minimization should be done for every operational period with account of overhauls performed and the time of their duration. Taking into account the above considerations we get (6.52) written as follows:

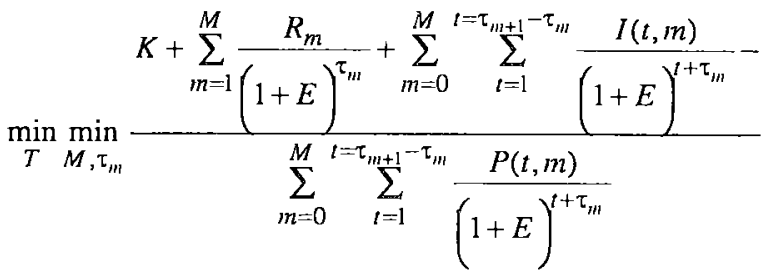

$$
-\frac{L}{(1+E)^{T}}
$$

here $I(t, m)$ - functions describing the changing of current expenses and train efficiency depending on train service life considered from the moment when overhaul $m$ was performed;

$m=0$ - corresponds to the moment of new train purchasing; $\tau_{M+1}=T$.

As we can see the costs of overhauls, their duration and intervals play an important part developing the models for determining the optimal service life of rolling stocks.

\section{Conclusions}

1. The rolling stock and the expected demand for trains make a variable. The calculations should regularly be made to determine the amount and type of trains needed at the particular time to ensure efficient freight and passenger transportation.

2. The calculation techniques used to determine the rolling stock have been mainly based on quantitative characteristics of trains. However, the methods relying on the evaluation of such qualitative characteristics as relative expenses, the efficiency of the particular train, its cost, etc. are also available.

3. The determination of the optimal service life of the rolling stock taking into account the costs of overhauls, their duration and intervals enables us to forecast more precisely the demand for trains.

\section{References}

1. Baublys A. Introduction to The Theory of Transport Systems (Transporto sistemos teorijos ivadas). Vilnius: Technika, 1997. 228 p (in Lithuanian).

2. Lingaitis L. P. Exploitation locomotives (Lokomotyvu eksploatavimas). Vilnius: Technika, 1997. 227 p (in Lithuanian).

3. Gridiuško V. I. Economics, organization and planning of rolling-stock fleet (Экономика, организация и планирование вагонного хозяйства). Moscow: Transport, 1980. $278 \mathrm{p}$ (in Russian).

4. Bodin L.; Mingozzi A.; Baldaccci R.; Ball M. The RollonRollof Vehicle Routing Problem. Transportation Science, 2000, Vol 34, No 3, August 2000.

5. Crainic T. G.; Florian M.; Lear J.-E. A Model for the Strategic Planning of National freight transportation by Rail. Transportation Science, Vol 24, No 1, February 1990.

6. SPAB „Lietuvos geležinkeliai“". Lithuania Railways. Development Programs of Lithuanian Railways till the Year 2015 (Lietuvos geležinkeliu plètros programa iki 2015 metu). Vilnius. 1999. 55 p (in Lithuanian). 